\title{
MEDITERRANEAN SPECIES FOR HEDGES IN SOLAR PHOTOVOLTAIC FARMS: A FOUR-YEAR STUDY.
}

\author{
SÁNCHEZ ORMEÑO M. \\ HERVÁS S. \\ AMORÓS J.A. \\ CAMPOS J. \\ PÉREZ-DE-LOS-REYES, C.*
}

Received: $13 / 01 / 2014$

Accepted: 09/05/2014

Available online: $28 / 05 / 2014$

\author{
School of Agricultural Engineering \\ University of Castilla-La Mancha \\ Ronda de Calatrava 7, 13071 Ciudad Real, Spain
}

\begin{abstract}
In an effort to reduce the environmental impact on the landscape caused by the installation of photovoltaic farms, Spanish legislation requires the establishment of a hedge on the perimeter of each plot.

The objective of the work described here was to increase our knowledge of the hedge species that are best adapted to the soil and climatic conditions of Mediterranean areas. Six species were planted on the perimeter of a photovoltaic farm: Olea europeae var. sylvestris, Pistacea lentiscus, Pistacea terebinthus, Quercus coccifera, Quercus ilex and Retama sphaerocarpa.

From 2009 to 2013 the survival percentages, apical growth, height and growth rate were studied for each species. Retama sphaerocarpa (91.7\%), Pistacia lentiscus (83.3\%) and Olea europaea var. sylvestris (70.8\%) had the highest survival percentages at the end of the study period. In the same period, for those species that surpassed a survival percentage of $50 \%$, the highest apical growths were shown by Retama Sphaerocarpa $(37.04 \mathrm{~cm})$, Pistacia lentiscus $(26.4 \mathrm{~cm}$ ) and Olea europaea var. sylvestris (25.8 $\mathrm{cm}$ ), with average growth rate of $13.79 \mathrm{~cm} \cdot \mathrm{year}^{-1}, 7.60 \mathrm{~cm} \cdot \mathrm{year}^{-1}$ and $7.14 \mathrm{~cm} \cdot$ year $^{-1}$, respectively. These three species are the best adapted to the conditions in Mediterranean areas for use as hedges.
\end{abstract}

Keywords: Survival percentage, apical growth, growth rate, species factor, Mediterranean areas.

\section{Introduction}

The installation of a photovoltaic farm involves the removal of the topsoil, land leveling and other actions such as compaction or addition of gravel. These actions lead to the modification of the original properties of the soil, the removal of natural vegetation and wildlife associated with it, and the acceleration of erosion due to the exposure of bare soil and lower levels of infiltration. The presence of solar panels is in itself a change in land use and is clearly detrimental to the natural landscape. Changes in land use have led to a widespread decrease in species diversity and species abundance in the Mediterranean area. These changes generally alter ecological process in land use that was regulated until recently by ancient traditions.

In an effort to reduce the environmental impact on the landscape caused by the installation of photovoltaic farms, the regional legislation requires the establishment of a hedge on the perimeter of the plot (Environmental Assessment Act of Castilla-La Mancha, 2007). Furthermore, the Regulation of Rural Land (Decree 242/2004) states that tree barriers must be planted in order to improve the 
integration into the environment of installations developed on rural land. Legislation indicates that plants must be native to the area and must be obtained from approved nurseries.

Hedgerows are an important component of the landscape and they may have an invaluable role in maintaining biological diversity. The origin of hedgerows and the type and intensity of their management are closely related to the composition of the species present. Apart from their function as corridors for some species, they may also act as 'reservoirs' for some woodland plants and as a refuge for wildlife. Hedges can also act as a barrier for other species and ecological processes (Schmitz et al., 2007). The role of hedges has been investigated throughout the world, especially as windbreaks, for limiting soil and water losses and for protecting adjacent croplands (Caubel et al., 2003).

Hedgerows potentially contribute to the cultural landscape and conservation planning, although many have been lost due to erroneous landscape planning. Loss of hedgerows can produce changes in environmental conditions and these can be especially critical in summer, which corresponds to the dry period in Mediterranean ecosystems (Sánchez et al., 2010).

It is known that native vegetation is best adapted to the soil and climatic characteristics of a particular region (Charco et al., 2008), a fact that makes such vegetation suitable to compensate for the impact of the installation of photovoltaic farms. The species that are mainly used in hedges in Mediterranean areas are from the mesomediterranean series: Retama sphaerocarpa, Olea europaea var. sylvestris, Rosmarinus officinalis, Cistus sp., Thymus sp., Lavandula stoechas, etc. (Schmitz et al., 2007).

The successful establishment of the hedge depends largely on where the plants grow and survival therefore depends largely on the ability of the plant to adapt and/or resist the limiting factors. In Mediterranean environments, the main limiting factor for the establishment of plants is the summer drought. Root elongation in order to increase the quantity of water supplied constitutes an adaptive strategy in species establishment: greater length and root surface leads to greater absorbance of the land water resource. This strategy is used by species such as Retama sphaerocarpa, which develops deep roots in the early months of field growth to access wetter soil layers (Padilla, 2008). Survival is greater when water is not a limiting factor for plant establishment. However, in seasonally dry environments such as the Mediterranean, survival is low due to plant losses caused by dehydration during the dry season (Castro et al., 2002; Gómez- Aparicio et al., 2004).

The presence of weeds can also severely limit the survival of the plants due to competition for the limited amount of soil water and nutrients (Rey Benayas et al., 2005).

Different native species, although adapted to environmental factors, respond differently to limiting factors. In some cases species that are characteristic of the Mediterranean ecosystem, such as Quercus coccifera and Quercus ilex, have lower survival rates when compared to other plant species (VillarSalvador et al., 2004; Padilla et al., 2004; Perez-de-los-Reyes et al., 2013), although they are recommended as revegetation species by the appropriate authorities. Species such as Pistacea lentiscus and Olea europea var. have high survival rates. As far as apical growth is concerned, these species also had the highest growth after eight years of study (Oliveira et al., 2011).

The choice of species is a key factor to ensure the best possible adaptation of plants against adverse environmental factors and will be therefore lower the economic cost of the process. Studies of the behavior of different plant species have previously been carried out after the first summer and this clearly only provides a short term view (Gómez- Aparicio et al., 2004; Rey Benayas et al., 2005; Padilla, 2008). It would be of scientific interest to determine how the species behave in the medium to long term. For this reason, the objective of the study reported here was to increase our knowledge of the species that are best adapted to Mediterranean climatic and soil conditions. The most appropriate species can then be used to shape hedges in areas degraded by solar photovoltaic farms and their behavior under field conditions can be assessed in the medium term. 


\section{Materials and methods}

\subsection{Location, climate and soil characteristics}

The work described here was carried out at the facilities of the Institute for Concentration Photovoltaic Systems (ISFOC) on the industrial estate 'La Nava III' in Puertollano (Ciudad Real, Castilla-La Mancha, Spain).

The area has an annual average temperature of 14.5 ㅇ $\mathrm{C}$ and an annual rainfall between 400 and 450 $\mathrm{mm}$. In accordance with the Papadakis classification the area is therefore a 'mild Mediterranean climate' (MMA, 2006).

The soil has a profile with four horizons, $\mathrm{Ap}(0-28 \mathrm{~cm}), \mathrm{Bt}_{1}(28-63 \mathrm{~cm}), \mathrm{Bt}_{2}(63-110 \mathrm{~cm})$ and $\mathrm{C}(>110$ $\mathrm{cm}$ ), with a sandy loam texture in the Ap horizon (12.9\% clay, $17.2 \%$ silt, $69.9 \%$ sand), sandy clay loam in the $\mathrm{Bt}_{1}(24.9 \%$ clay, $17.2 \%$ silt, $57.9 \%$ sand $)$ and clay in the $\mathrm{Bt}_{2}(52.9 \%$ clay, $9.2 \%$ silt, $37.9 \%$ sand). The organic matter content is high for the Ap horizon (2.8\%). The soil is classified as Typic Rhodoxeralf. The vegetation in the area is similar to oak trees on a silicon substrate, in the province CastellanoMaestrazgo-Manchega, in which natural vegetation includes the species used in this work (Peinado et al., 2008).

\subsection{Experimental design}

In order to achieve the objectives a vegetation screen was created with 6 native species. The six species were as follows: Olea europeae var. sylvestris, Pistacea lentiscus, Pistacea terebinthus, Quercus coccifera, Quercus ilex and Retama sphaerocarpa. All selected species were native, typical of the Mediterranean areas with low water requirements, well adapted to adverse conditions and of different morphology.

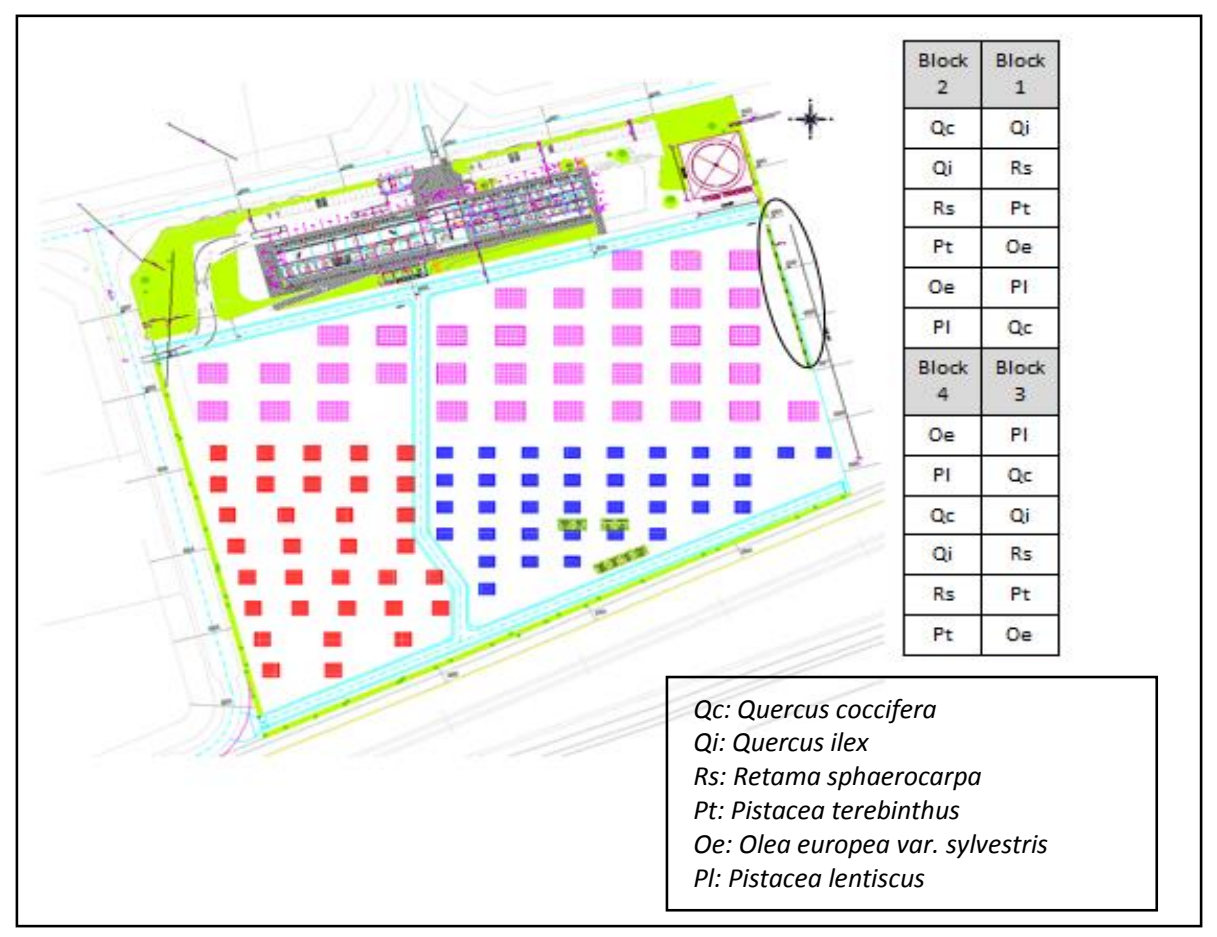

Figure 1. Overview of facilities (ISFOC)

The experimental design was carried out in randomized blocks. One-year-old plants for each species were planted in April of 2009 in four blocks. Seedlings were obtained from an authorized nursery. There were 24 plants per species, 36 plants per block or 144 plants in total. The plants were separated from each other by a distance of one meter and they were planted one meter from the fence that bordered the plot. The location chosen for the study and the arrangement of the species in the different blocks 
are shown in Figure 1. Support irrigation was carried out in May and June and manual weeding was carried out in June.

During the period 2009-2013 the survival rate of each species and apical growth of each plant were recorded.

\subsection{Statistical analysis}

Statistical analysis was carried out using the computer program STATGRAPHICS Plus 5.1 (Copyright $^{\odot}$ 1994-2000 Statistical Graphics Corp.). Survival data were subjected to a chi-squared test for independence $(P<0.01)$. Growth data were analyzed using the Kruskal-Wallis test to check the null hypothesis of equal medians at a confidence level of $95 \%$.

\section{Results}

\subsection{Survival percentage}

The results obtained for the survival percentage (number of live plants/number of planted plants $\times 100$ ) for each species are represented in Figure 2.

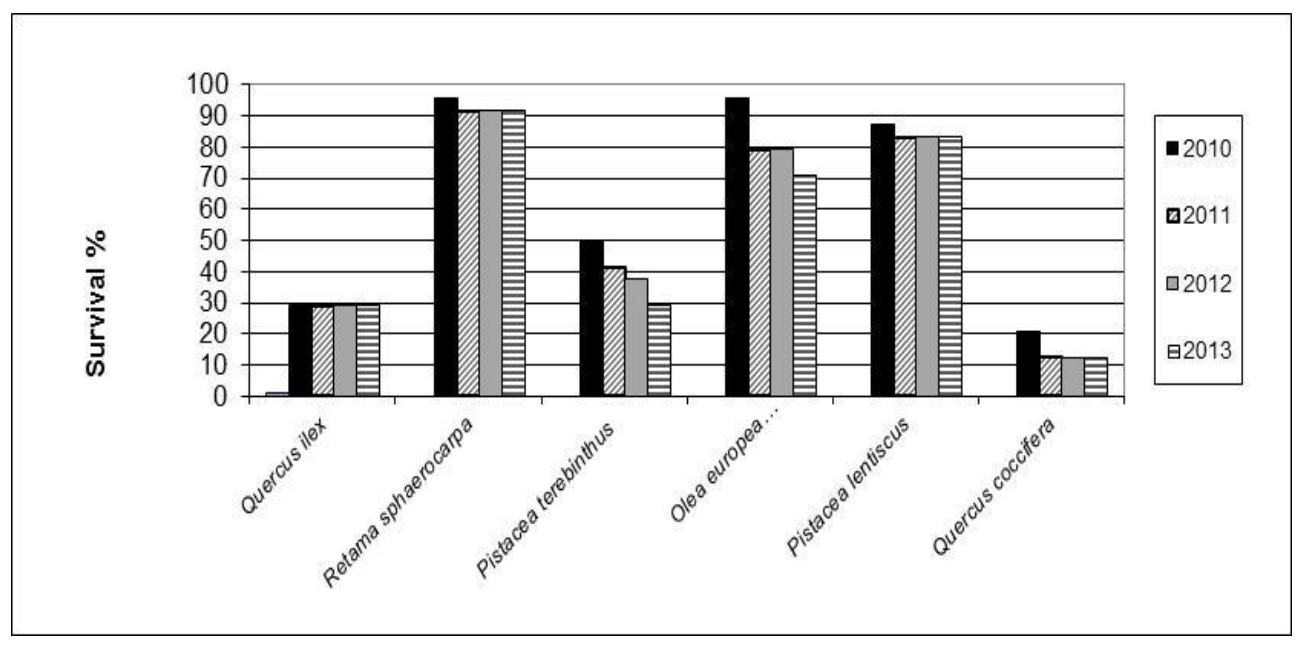

Figure 2. Survival percentages of the species investigated

Species of the genus Quercus stand out as having the lowest survival percentages while Retama sphaerocarpa, Olea europea var. sylvestris and Pistacia lentiscus are those species that had the highest survival rates over the study period.

In 2013 (final year of the study), the species that exceeded 50\% survival were also Retama sphaerocarpa (91.7\%), Olea europaea var. sy/vestris (70.8\%) and Pistacia lentiscus (83.3\%).

The chi-square test for the hypothesis of independence shows that the species factor influenced the survival of plants with a confidence level of $99 \%$ in all years of study $\left(X^{2}=60.34 ; 54.40 ; 53.55 ; 53.05\right.$ and 53.46 , respectively, 5 degrees of freedom, $p<0.01$ ).

\subsection{Apical growth, height and growth rate}

In this section three parameters have been studied: apical growth, height and growth rate (for species that exceeded $50 \%$ survival). Apical growth values were calculated, as the difference between the final length and the initial length taken for the longest stem and considering only positive increases, as suggested by Oliveira et al. (2011). Height values were calculated as the average of the height of the plants for each studied year and the growth rate was calculated as apical growth per year for each species. 
Among the species used in the hedge, only Retama sphaerocarpa, Olea europaea var. sylvestris and Pistacia lentiscus had a survival rate above $50 \%$ at the end of the study (see Figure 2). The apical growth data of these species during the study period (2009-2013) are represented in Figure 3.

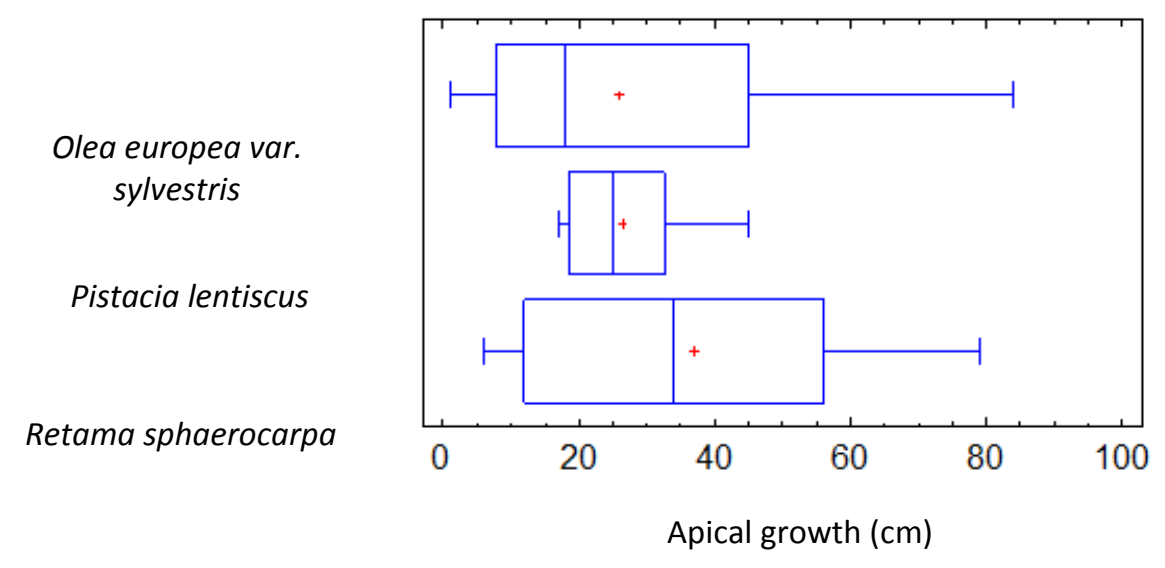

Figure 3. Scatter plot of the apical growth values for hedgerow species over four years.

The Kruskal-Wallis test was used to confirm that the median values of the apical growth for the different species were not significantly different, at a confidence level of $95 \%$. It was found that the species factor did not affect apical growth under the conditions of this experiment.

After four years, the fastest growing species were, from highest to lowest, Retama sphaerocarpa $(37.04 \pm 25.28 \mathrm{~cm})$, Pistacia lentiscus $(26.4 \pm 8.51 \mathrm{~cm})$ and Olea europaea var. sylvestris $(25.8 \pm 22.75 \mathrm{~cm})$.

The annual evolution of the height of the hedge species that exceeded $50 \%$ survival is represented in Figure 4.

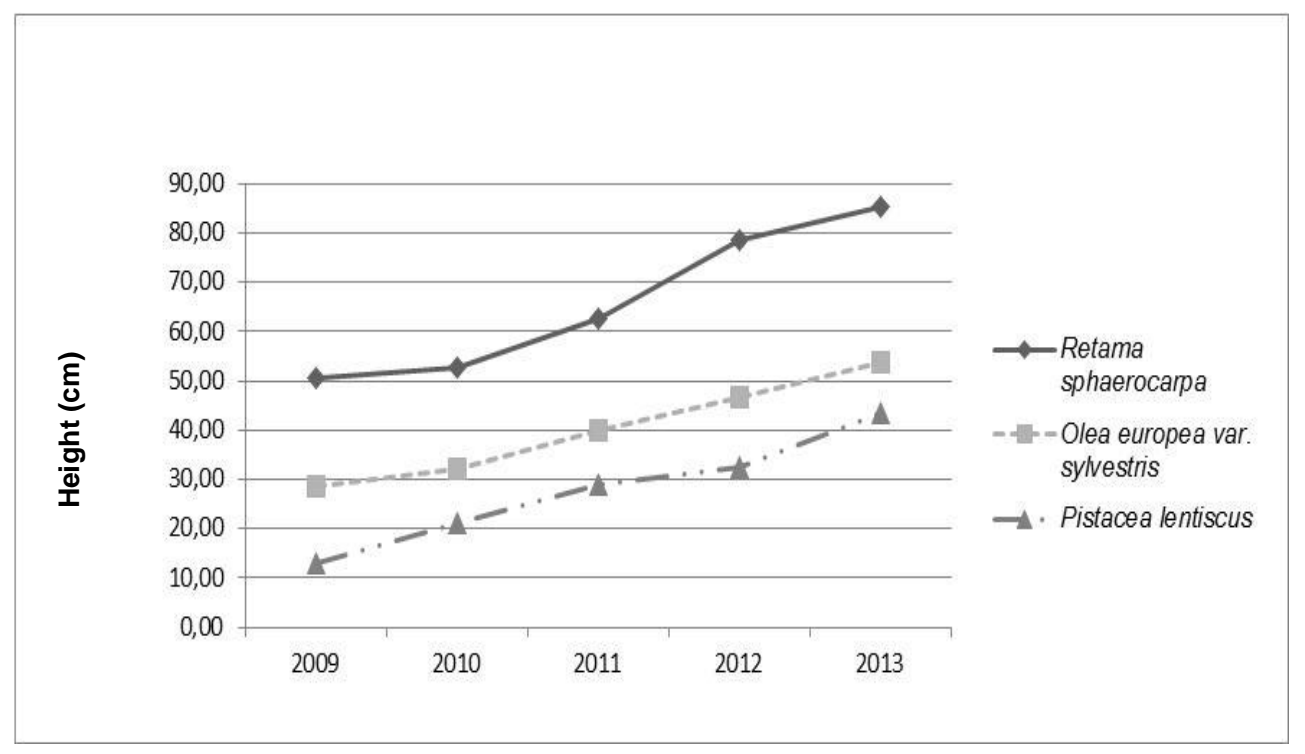

Figure 4. Evolution of height of the species throughout the study period

It can be observed that the three species show a progressive longitudinal evolution. While Retama sphaerocarpa had a mean height of $82 \mathrm{~cm}$, Olea europeae var. sylvestris and Pistacea lentiscus had mean heights of 58 and $42 \mathrm{~cm}$, respectively, and these species are significantly shorter than Retama sphaerocarpa. 
The average annual growth rate values $\left(\mathrm{cm} \cdot \mathrm{year}^{-1}\right)$ are represented in Figure 5 . The species that had the highest growth rate was Retama sphaerocarpa, with an average growth per year of $13.79 \mathrm{~cm}$, followed by Pistacia lentiscus with $7.60 \mathrm{~cm}$ and, finally, Olea europaea var. sylvestris with $7.14 \mathrm{~cm}$.

The highest growth rates for Retama sphaerocarpa $\left(21 \mathrm{~cm} \cdot y e a r^{-1}\right)$ and Olea europaea var. sylvestris $\left(11.5 \mathrm{~cm} \cdot\right.$ year $\left.^{-1}\right)$ were observed in the second year. However, the highest growth rate for Pistacia lentiscus was observed in the second and fourth years, with values of $10 \mathrm{~cm} \cdot y e a r^{-1}$.

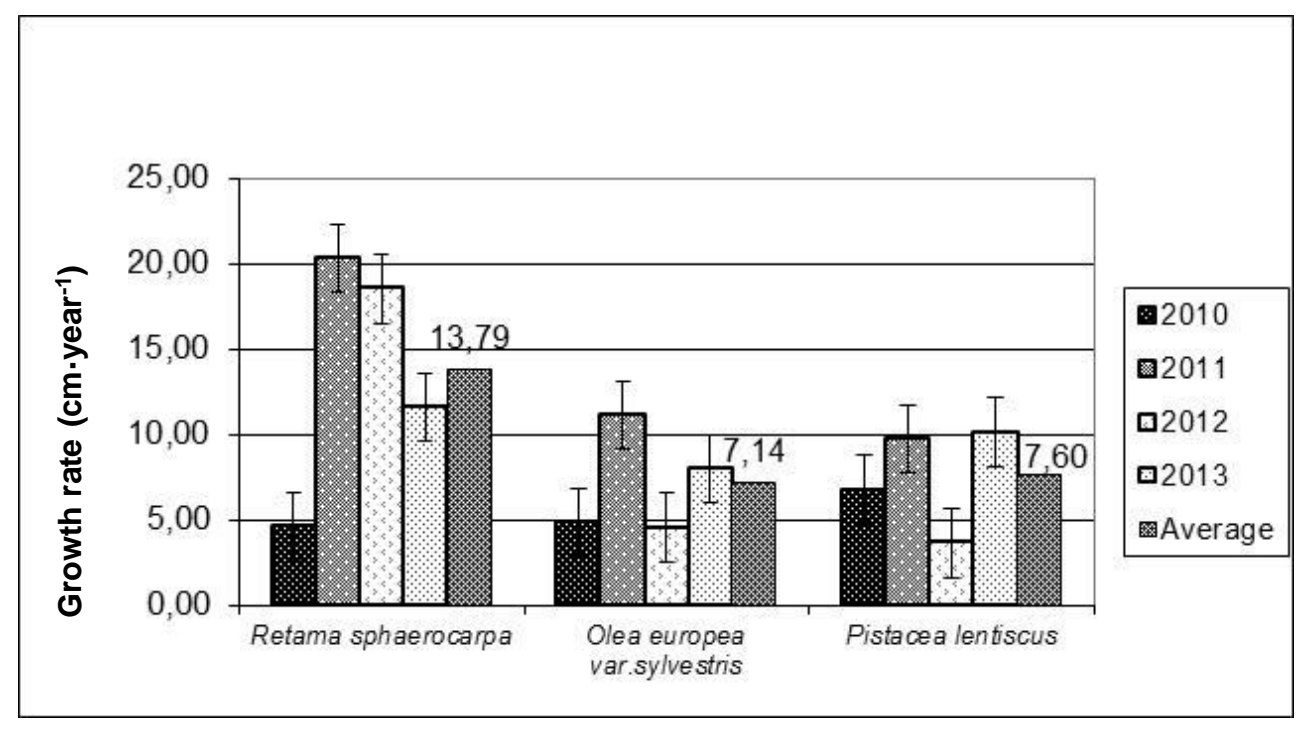

Figure 5. Growth rate $\left(\mathrm{cm}\right.$ year $\left.{ }^{-1}\right)$ of the species throughout the study period

\section{Discussion}

\subsection{Survival percentage}

In Mediterranean environments, the summer after planting is the most critical period for plant survival (Gómez-Aparicio et al., 2004; Rey Benayas et al., 2005; Verdaguer et al., 2011) because it depends on the climatic characteristics and soil, which will allow correct root development (Burdett, 1990; Padilla, 2008; Verdaguer et al., 2011).

In this study, plants of the genus Quercus stand out as having the lowest survival percentage after the first year of planting. However, after this first year the survival percentages of Quercus ilex $(29.17 \%)$ and Quercus coccifera (12.50\%) remained constant during the study period. In the same year the genera Olea and Retama showed the highest survival rates. The survival percentage of the genus Olea progressively decreases over the years, except for the second and third years, during which it remains constant. In contrast, Retama sphaerocarpa had a constant survival percentage after the first two years $(91.67 \%)$ and similar behavior was shown by Pistacia lentiscus, which has a value of $83.33 \%$ after the first two years.

Olea europea var. sylvestris and Pistacia lentiscus have been recommended for the revegetation of quarries in Mediterranean areas (Oliveira et al., 2011) and, after eight years of study, they had very high survival rates ( $94 \%$ and $95 \%$, respectively). On the other hand, Retama sphaerocarpa had a survival rate of $83 \%$ at the end of a three-year experiment conducted outside Almería by Padilla et al. (2009) and it was concluded that survival among successional species, like leguminous species, was higher than that among late successional species such as Olea europea var. sylvestris and Pistacia lentiscus. The difference in survival between species can be explained as being due to the different ranges of tolerance to water stress (Vilagrosa et al., 2003).

Quercus coccifera and Quercus ilex, which are recommended by the regional administration for the formation of hedges, had the lowest survival rates when compared with other Mediterranean species 
(Villar-Salvador et al., 2004; Padilla et al., 2004; Pérez-de-los-Reyes et. al., 2013). This could be related to soil properties because Quercus ilex and Quercus coccifera prefer calcareous soils (in the plot the soil pH was slightly acidic).

The findings outlined above do not mean that these species must been ruled out for hedges. In arid and semi-arid areas it is recommended that restoration is based on the beneficial interaction between different species (known as 'facilitation') (Gómez-Aparicio et al., 2004; Badano et al., 2009) to reduce environmental stress, especially under ambient conditions of water shortage. Therefore, the use of multispecies hedgerows is recommended to ensure multi-layered vegetation (Andreu et al., 1998; Li et al., 2011).

\subsection{Apical growth, height and growth rate}

After four years the fastest growing species were, in descending order, Retama sphaerocarpa, Pistacia lentiscus and Olea europaea var. sylvestris. Retama Sphaerocarpa is characterized as a fast-growing leguminous species and it is highly adapted to deforested land. For this reason, authors such as Padilla et al. (2009) recommend this species for restoration or hedges. Pistacia lentiscus is also well suited to deforested and degraded lands and Olea europaea var. sylvestris is usually chosen for its hardiness (Charco et al., 2008). In the study by Oliveira et al. (2011) it was established that Pistacia lentiscus exhibited the most regular apical growth throughout this period, while the apical growth of Olea europea var. sylvestris tended to increase at the end of the study period.

In our study, Retama sphaerocarpa is the species that has the highest height, growth rate and it is also the species with the highest apical growth. The same trend in terms of growth rate/apical growth/height was observed for the other species Pistacia lentiscus and Olea europaea var. sylvestris. Therefore, growth rate is directly related to the apical growth of the plant species studied.

\section{Conclusions}

A four-year study was carried out on six species for hedge formation. The species factor influenced the survival percentage but it did not affect the apical growth of the species that had a survival level above 50\% (Retama sphaerocarpa, Olea europaea var. sylvestris and Pistacia lentiscus).

The three species listed above showed high survival percentages and a progressive height evolution over the four years of study. For these reasons the three species can be recommended as being suitable for the establishment of hedges in solar farms in Mediterranean areas.

The species Quercus ilex and Quercus coccifera showed the lowest survival percentages, although they are characteristic of the Mediterranean ecosystem and they are important for the formation of multilayered hedges.

\section{Acknowledgements}

The authors are grateful to Mr Oscar de la Rubia and Mr Ángel Hipólito from the Institute for Concentration Photovoltaic Systems (ISFOC) for their contribution to the research. Appreciation is also extended to Dr Neil Thompson for assistance with language editing.

This work is funded by the research project 'SIGMAPLANTAS: Innovation in farms and photovoltaic concentrating systems models in Spain (IPT-2011-1468-92000)' from the Ministry of Science and Innovation (Spain).

\section{References}

Andreu V., Rubio J.L., Gimeno-Garcia E. and Llinares, J.V. (1998), Testing three Mediterranean shrub species in runoff reduction and sediment transport, Soil Till. Res., 45, 441-454.

Badano E.I., Pérez D. and Vergara C.H. (2009), Love of nurse plants is not enough for restoring oak forest in a seasonally dry tropical environment, Restor. Ecol., 17(5), 571-576, doi: 10.1111/j.1526-100X.2009.00530.x.

Burdett A.N. (1990), Physiological processes in plantation establishment and the development of specifications for forest planting stock, Can. J. Forest. Res., 20(4), 415-427, doi: 10.1139/x90-059. 
Castro J., Zamora R., Hódar J.A. and Gómez J.M. (2002), Use of shrubs as nurse plants: a new technique for reforestation in Mediterranean mountains, Restor. Ecol., 10(2), 297-305, doi: 10.1046/j.1526100X.2002.01022.x.

Caubel V., Grimaldi C., Merot P. and Grimaldi M. (2003), Influence of a hedge surrounding bottomland on seasonal soil-water movement, Hydrological processes, 17, 1811-1821.

Charco J., Fernández F., García R, Mateo G. and Valdés A. (2008), Árboles y arbustos autóctonos de Castilla-La Mancha, Centro de Investigaciones Ambientales del Mediterráneo, Ciudad Real. Spain.

Environmental Assessment Act of Castilla-La Mancha (2007), Official Gazette. (BOE) http://www.boe.es/boe/dias/2007/05/17/pdfs/A21033-21051.pdf (In Spanish)

Gómez-Aparicio L.; Zamora R., Gómez J.M., Hódar J.A., Castro J. and Baraza E. (2004), Applying plant facilitation to forest restoration: a meta-analysis of the use of shrubs as nurse plants, Ecol. Appl., 14(4), 1128-1138, doi: $10.1890 / 03-5084$.

Li J.Q., Zhang H.J., Cheng J.H., Wang X. and Lu-Xing W. (2011), Soil physical properties of different hedgerow systems in upper reaches of Yangtze River, Chinese Journal of Applied Ecology, 22(2), 418-424.

MMA, Ministry of Environment. (2006), Guidelines for the preparation of physical environment studies, Ministry of Environment, Madrid. Spain, (In Spanish).

Oliveira G., Nunes A., Clemente A. and Correira O. (2011), Effect of substrate treatments on survival and growth of Mediterranean shrubs in a revegetated quarry: An eight-year study, Ecol. Eng., 37, 255-259, doi: 10.1016/j.ecoleng.2010.11.015.

Padilla F.M. (2008), Limiting factors and strategies for establishment of woody plants in semi-arid environments. Implications for restoration, Ecosistemas, 17(1), 155-159. (In Spanish)

Padilla F.M., Ortega R., Sánchez J. and Pugnaire F.I. (2009), Rethinking species selection for restoration of arid shrublands, Basic Appl. Ecol., 10, 640-647, doi: 10.1016/j.baae.2009.03.003.

Padilla F.M., Pugnaire F.I., Marín R., Hervás M. and Ortega R. (2004), Use of shrubs for vegetation cover restoration in semi-arid environments, Cuadernos de la Sociedad Española de Ciencias Forestales, 17, $103-107$. (In Spanish)

Peinado M., Monje L. and Martínez J.M. (2008), The vegetation landscape of Castilla-La Mancha. Junta de Comunidades de Castilla La Mancha, Toledo. Spain. (In Spanish)

Perez-de-los-Reyes C, Sánchez Ormeño M, Amorós J.A., García Navarro F.J., Campos J., Martínez Lòpez R., Rubio F. and De la Rubia O. (2013), Revegetation in solar photovoltaic farms in Mediterranean areas, Fresenius Environmental Bulletin, 22(12a), 3680 - 3688.

Rey Benayas J.M., Navarro J., Espigares T., Nicolau J.M. and Zavala M.A. (2005), Effects of artificial shading and weed mowing in reforestation of Mediterranean abandoned cropland with contrasting Quercus species, Forest Ecol. Manag., 212, 302-314.

Sánchez I.A., Lassaletta L. and McCollin D. (2010), The effect of hedgerow loss on microclimate in the Mediterranean region: an investigation in Central Spain, Agroforest Syst., 78, 3-25, doi: 10.1007/s10457-0099224-z.

Schmitz M.F., Sánchez I.A. and de Aranzabal I. (2007), Influence of management regimes of adjacent land uses on the woody plant richness of hedgerows in Spanish cultural landscape, Biological conservation, 135, 542-554.

Verdaguer D., Vilagran J., Lloansi S. and Fleco I. (2011), Morphological and physiological acclimation of Quercus coccifera L. seedling to water availability and growing medium, New Forests, 42(3), 363-381, doi: $10.1007 /$ s11056-011-9257-9

Vilagrosa A., Cortina J., Gil-Peregrín E. and Bellot E. (2003), Suitability of drought-preconditioning techniques in Mediterranean climate, Restor. Ecol., 11(2), 208-216, doi: 10.1046/j.1526-100X.2003.00172.x.

Villar-Salvador P., Planelles R., Enríquez, E. and Peñuelas J. (2004), Nursery cultivation regimes, plant functional attributes, and field performance relationships in the Mediterranean oak Quercus ilex L., Forest Ecol. Manag., 196, 257-266. 